\title{
A Three Year Retrospective Study of Caesarean Section Rate at Tanta University Hospitals
}

\author{
Ayman Shehata Dawood ", Abdel-Ghafar Said Dawood, Shereef Lotfy El-Shwaikh
}

Department of Obstetrics and Gynecology, Faculty of medicine, Tanta University, Tanta, Egypt

\section{Email address:}

ayman.dawood@med.tanta.edu.eg (A. S. Dawood), ghafar123456789@hotmail.com (Abdel-Ghafar S. D.), Shereef.lotfy@med.tanta.edu.eg (S. L. El-Shwaikh)

*Corresponding author

\section{To cite this article:}

Ayman Shehata Dawood, Abdel-Ghafar Said Dawood, Shereef Lotfy El-shwaikh. A Three Year Retrospective Study of Caesarean Section Rate at Tanta University Hospitals. Journal of Gynecology and Obstetrics. Vol. 5, No. 2, 2017, pp. 25-30. doi: 10.11648/j.jgo.20170502.11

Received: February 22, 2017; Accepted: March 6, 2017; Published: March 24, 2017

\begin{abstract}
This Retrospective observational study was done to determine the actual Caesarean Section rate at Tanta University Hospitals (a tertiary care hospital). Review of all deliveries that have been conducted at Tanta University Hospitals whether Vaginal or Caesarean Section in the period from January 1, 2013 to December 31, 2015 and detection of the most common causes of the Caesarean Section. The total number of deliveries was 3592, 3342, and 3320 in the years 2013, 2014 and 2015 respectively. The Rate of cesarean section was (1049/3592) 41\% in 2013, (1004/23342) 45\% in 2014, and (1057/3320) $46 \%$ in 2015. The CS rate was high at Tanta University Hospital, and there was slight increase in the rate through the period of study. The most common indication for cesarean section was previous cesarean section. The conclusion is that the rate of cesarean section was so high at Tanta University Hospital and much higher than WHO recommendation for developing countries. The rate of cesarean section showed minimal but continuous rise in the past three years.
\end{abstract}

Keywords: Caesarean Section Rate, Epidemic, Tertiary Care Hospitals

\section{Introduction}

The incidence of Caesarean deliveries is increasing every day passing faraway beyond WHO recommended rate of $15 \%$ for all deliveries [1]. Many factors contribute for the rising rates of Caesarean delivery including maternal characteristics, malpractice, economic, social and medicolegal factors have all been reported. [2]

Other important but underestimated factors include women request, hospital system factors, obstetrician's qualification and type of care provided by insurance. All of these factors are complex, and non-separable. [3]

Caesarean delivery rates are shooting all over the world with a rate of $(40.5 \%)$ in Latin America and the Caribbean region which was the highest regions with CS rates followed by Northern America with a rate of (32.3\%), Oceania (31.1\%), Europe (25\%), Asia (19.2\%) and Africa (7.3\%). [4]

Cesarean birth rates are also increasing in Turkey in parallel to the developments in the world. While $6.0 \%$ of all births were realized by cesarean section in 1998, this rate has risen to $48.1 \%$ in 2013. [5] In Japan a retrospective study done at 125 institutions and concluded that the overall CS rate was found to be $37.3 \%$. [6]

In Australia the rate of CS was increased from $19.22 \%$ in the year 1995 to $33.6 \%$ in the year 2010. It was also reported that CS rates are higher in private hospitals than public hospitals where the CS rate was $31.8 \%$ in 2007 but, women delivered in private health insurance hospital the rate was $41.5 \%$ compared with women who delivered in public hospitals. [7]

In Egypt, WHO stated that the Caesarean section (CS) rate in Egypt was 27.6\% in the year 2010. [8] According Ministry of Health and Populations reported data; more than 50\% $(50.8 \%)$ of all deliveries were by CS without much difference between urban and rural areas. [9, 10] The possible factors employed in the rising CS rates were fear of labour pains; misconception about genital damage after vaginal delivery; misconception about safety of CS delivery for the baby; 
medico-legal issues and responsibilities if fetus was lost in normal labour, health professionals a financial issues and lower tolerance to any complications or outcomes other than the perfect baby. [11] Another non-medical factors control the time and type of delivery, for example in China, scheduling CS and choosing the time of CD delivery is linked to luck and fate for the future of the baby. $[12,13]$

On the other hand, several European countries have managed to control their CS rates over time by strict management of vaginal deliveries and strict policies on requesting CS plus legal framework for medical litigation. $[14,15]$ Also the trend to apply vaginal birth after cesarean section decreased the rate of cesarean section. [16]

The rate is unknown at Tanta University Hospitals so we conducted this study to determine the actual rate of CS at a tertiary care hospital.

\section{Materials and Methods}

This study is retrospective observational study done at Department of Obstetrics and Gynecology, Patient affairs and statistics unit of Tanta University, Egypt.

The hospital is located at the center of Nile Delta and serves the population of four provinces, it has 85 beds for patients with obstetrics or gynecology problems, it serves the patients with very minimal fees, and sometimes free of charges.

It is tertiary care hospital and referral hospital for many small hospitals in four provinces for any complicated cases, or difficult case.

The records of obstetrics patients are regulated by the regulations of the hospital and every case is recorded for her age, date of admission, date of delivery, type of delivery, indication of cesarean section, gender of newborn and his health, any possible complications and the name of obstetricians who conduct the delivery.

The records of patients had been reviewed from January 1, 2013 to December 31, 2015 for number of cesarean section, number of vaginal delivery, indications of cesarean section and complications to show the actual rate of cesarean in tertiary care hospital.

This study was approved by the committee of ethics of Tanta University. The records of patients had been reviewed after permission of the ethical committee of Tanta University and with privacy and preserving every single detail about patients and doctors.
The indications of cesarean section had been grouped and classified according to its indications and according to The Modified Robson Criteria. [17, 18]

\section{Results}

This study was done retrospectively collecting all data about deliveries conducted at Tanta University Hospitals in the period from January, 1, 2013 till December, 31, 2015. The total number of deliveries was 3592, 3342, and 3320 in the years 2013, 2014 and 2015 respectively. The Rate of cesarean section was $(1049 / 3592) 41 \%$ in 2013, (1004/23342) 45\% in 2014, and (1057/3320) 46\% in 2015.

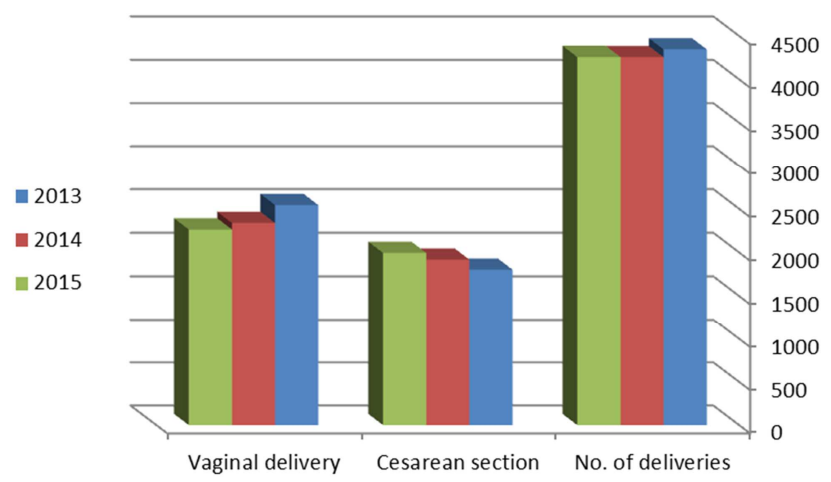

Figure 1. Shows rate of cesarean section.

The indications of cesarean due to breech presentation had been separated from other malpresentaions, also the twins pregnancy had been separated from patients with high order multiple pregnancy and this had been done to be more determined in the indication of section.

The indications of medical disease of section, is any medical condition necessitate section not related to obstetrics complications like cardiac patients or cancer patients, and only single case the indication of cesarean was previous history of renal transplantation.

The most common indication of cesarean section in Tanta University Hospitals was previous cesarean section while IUGR, oligohydarminos, antepartum hemorrhage, failed trail and CPD come in second place. The least common indications were malpresentaions other than breech, high order multiple pregnancies, chorioamnoitis and medical disease. Table 1

Table 1. Indications of cesarean section at Tanta University Hospitals during study period.

\begin{tabular}{|c|c|c|c|}
\hline & 2013 & 2014 & 2015 \\
\hline \multirow{2}{*}{ previous CS } & 1049 & 1004 & 1057 \\
\hline & $58.1 \%$ & $52.3 \%$ & $52.9 \%$ \\
\hline \multirow{2}{*}{ Fetal distress } & 65 & 56 & 58 \\
\hline & $3.6 \%$ & $2.9 \%$ & $2.9 \%$ \\
\hline \multirow{2}{*}{ IUGR and oligohydraminos } & 97 & 130 & 134 \\
\hline & $5.3 \%$ & $6.7 \%$ & $6.7 \%$ \\
\hline \multirow{2}{*}{ Antepartum hemorrhage } & 86 & 123 & 126 \\
\hline & $4.7 \%$ & $6.4 \%$ & $6.3 \%$ \\
\hline \multirow{2}{*}{ Cephalopelvic disproportion } & 171 & 143 & 144 \\
\hline & $9.4 \%$ & $7.4 \%$ & $7.2 \%$ \\
\hline
\end{tabular}




\begin{tabular}{|c|c|c|c|}
\hline & 2013 & 2014 & 2015 \\
\hline \multirow{2}{*}{ Failed trail } & 128 & 174 & 178 \\
\hline & $7 \%$ & $9 \%$ & $8.9 \%$ \\
\hline \multirow{2}{*}{ Breech } & 58 & 51 & 58 \\
\hline & $7 \%$ & $2.6 \%$ & $2.9 \%$ \\
\hline \multirow{2}{*}{ Other malpresentation } & 16 & 18 & 20 \\
\hline & $0.88 \%$ & $0.93 \%$ & $1 \%$ \\
\hline \multirow{2}{*}{ Twins } & 47 & 76 & 78 \\
\hline & $2.6 \%$ & $3.9 \%$ & $3.9 \%$ \\
\hline \multirow{2}{*}{ High order multiple pregnancy } & 16 & 9 & 6 \\
\hline & $0.88 \%$ & $0.46 \%$ & $0.3 \%$ \\
\hline \multirow{2}{*}{ Chorioamnoitis } & 12 & 13 & 10 \\
\hline & $0.66 \%$ & $0.67 \%$ & $0.5 \%$ \\
\hline \multirow{2}{*}{ Patient request } & 39 & 86 & 90 \\
\hline & $2.1 \%$ & $4.4 \%$ & $4.5 \%$ \\
\hline \multirow[b]{2}{*}{ Medical disease } & 19 & 35 & 36 \\
\hline & $1 \%$ & $1.8 \%$ & $1.8 \%$ \\
\hline
\end{tabular}

Table 2. Indications of cesarean section according to Modified Robson Criteria.

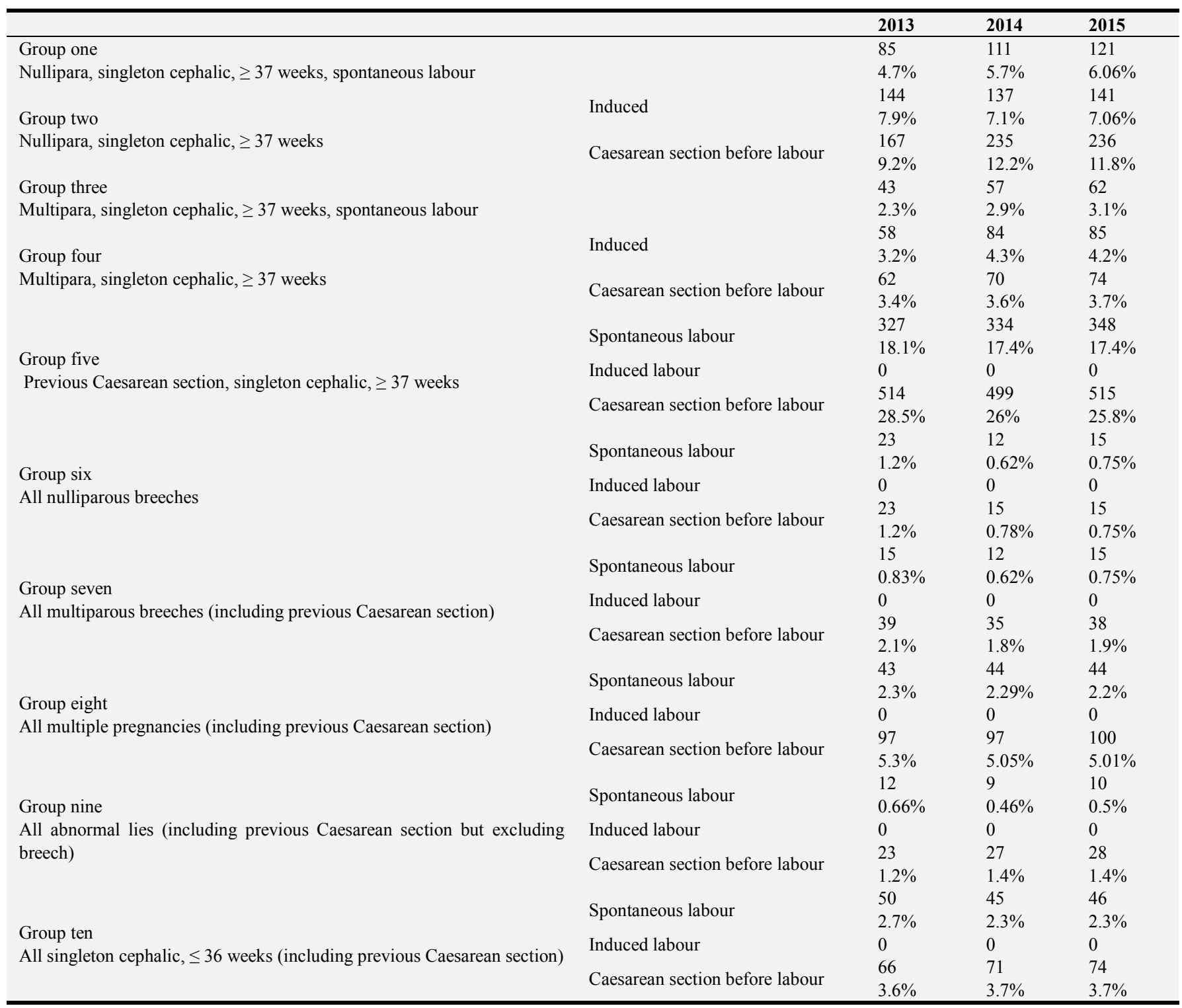

After application of Modified Robson Criteria to determine the indications of cesarean section at Tanat University Hospital we can notice that:
- Group five (spontaneous labour and before labour) is the most common group subjected to cesarean section

- Group two is the second most common group subjected 
to cesarean section

- Group eight (spontaneous labour and before labour) is the third most common group.

- There is no recorded cases for induction of labour for groups five, six, seven, eight, nine and ten. Table 2

As regard complications following vaginal delivery, infection complications range from simple episiotomy infection or disruption to sever form of puerperal sepsis, genital organ injuries are vaginal tears, cervical tears and rupture uterus, also fetal complications range from simple tachypnea and low Apgar score to severe distress and intrapartum fetal loss.

Breaking episiotomy scar was the most common complication, genital tract injury was the second most common, while uterine inversion and thromboembolic complications are very rare. Table 3

Table 3. Rate of complications in patients after vaginal delivery.

\begin{tabular}{llll}
\hline & $\mathbf{2 0 1 3}$ & $\mathbf{2 0 1 4}$ & $\mathbf{2 0 1 5}$ \\
\hline No. of delivery & 2543 & 2338 & 2263 \\
Infection & 84 & 45 & 33 \\
Hematoma & $3.3 \%$ & $1.9 \%$ & $1.4 \%$ \\
Postpartum hemorrhage & 14 & 12 & 15 \\
& $0.5 \%$ & $0.5 \%$ & $0.66 \%$ \\
Breaking of episiotomy scar & 42 & 35 & 33 \\
& $1.6 \%$ & $1.4 \%$ & $1.4 \%$ \\
Genital organ injury & $8.8 \%$ & 220 & 198 \\
Complete perineal tear & 187 & $9.4 \%$ & $8.7 \%$ \\
Postpartum psychosis & $7.3 \%$ & 158 & 145 \\
& 12 & $6.7 \%$ & $6.4 \%$ \\
Retained placenta & $0.47 \%$ & 9 & 8 \\
& 4 & $0.38 \%$ & $0.35 \%$ \\
Uterine inversion & $0.15 \%$ & 3 & 4 \\
Thromboembolic & 44 & $0.12 \%$ & $0.17 \%$ \\
complications & $1.7 \%$ & 25 & 47 \\
Fetal complications & 2 & $1.06 \%$ & $2.07 \%$ \\
\hline
\end{tabular}

Table 4. Rate of complications in patients after caesarean section.

\begin{tabular}{llll}
\hline & $\mathbf{2 0 1 3}$ & $\mathbf{2 0 1 4}$ & $\mathbf{2 0 1 5}$ \\
\hline No. of delivery & 1049 & 1004 & 1057 \\
Infection & 158 & 178 & 184 \\
& $15 \%$ & $17 \%$ & $17 \%$ \\
Hematoma & 14 & 15 & 10 \\
Postpartum hemorrhage & $1.3 \%$ & $1.4 \%$ & $0.9 \%$ \\
Breaking of pfennestiel incision & 18 & 14 & 15 \\
& $1.7 \%$ & $1.3 \%$ & $1.4 \%$ \\
Urinary system injury & $45 \%$ & 47 & 32 \\
Other abdominal organs injury & 17 & $19 \%$ & $1.6 \%$ \\
Postpartum psychosis & $1.6 \%$ & $1.8 \%$ & 23 \\
& 0 & 1 & $3.02 \%$ \\
Hysterectomy & 1 & $0.09 \%$ & 0 \\
Postpartum ileus & $0.09 \%$ & 0 & 0 \\
\hline
\end{tabular}

\begin{tabular}{llll}
\hline & $\mathbf{2 0 1 3}$ & $\mathbf{2 0 1 4}$ & $\mathbf{2 0 1 5}$ \\
\hline \multirow{2}{*}{ Thromboembolic complications } & 12 & 18 & 24 \\
& $0.66 \%$ & $1.7 \%$ & $2.2 \%$ \\
Anesthetic complications & 12 & 10 & 18 \\
& $1.1 \%$ & $0.9 \%$ & $1.7 \%$ \\
Fetal complications & 25 & 24 & 13 \\
& $2.3 \%$ & $2.3 \%$ & $1.2 \%$ \\
\hline
\end{tabular}

Complications of cesarean section itself not to the indications of cesarean section were infections complications range from simple wound infection to peritoneal abscess, hysterectomy complication was due to uncontrolled hemorrhage or sever injury to uterus, the hysterectomy done for placenta accrete were excluded as that hysterectomy is due to placental pathology not due to cesarean section itself, fetal complications range from simple cut injury to the baby and transient tachypnea of newborn to severe form of fetal distress.

Infection was the most common complication; breaking of pfanestiel incision is the second most common. Postpartum psychosis and abdominal organ injury other than urinary system are very rare. Table 4

\section{Discussion}

This retrospective observational study had been conducted at Department of Obstetrics and Gynecology, Patient affairs and statistics unit of Tanta University, Egypt. All deliveries that occurred from 1 January 2013 till 31 December 2015 were reviewed as regard patient age, parity, residence and type of delivery and any complications occurred.

There was no significant difference in the number of deliveries in the three years, and there is slight rise in the no. of cesarean section from 2013 (41\%) to 2014 (45\%) to reach $46 \%$ in 2015 .

by comparing Tanta University Hospital's rates with other Egyptian university hospitals' rates we found that Alaa-Eldin Ebrashy et al (2011) determined and compared the rates and indications of CS deliveries in Cairo University Hospital and Al Mattaria Teaching Hospital they found that the rate of cesarean section was (37.8\%) and (36.5\%) at Cairo University Hospital and Al Mattaria Teaching Hospital respectively with the most important indication was the previous cesarean section scar and the other common indications were the cephalopelvic disproportion and failed trial[19] Another study for determining Caesarean rate at Cairo University Hospital was determined by El Khyat et al (2013) at 5 year period where they found that the rate of Cesarean sections was gradually increasing from $38.84 \%$ of deliveries in 2008, to $41.17 \%$ in 2012. [20]

At Ain Shams University Hospitals Ihab Serag et al (2014) conducted a study to evaluate the incidence of peripartum emergency hysterectomy in 5-year retrospective study starting at 2003 till end of 2008. They found that Caesarean rate increased from $31 \%$ at 2004 to $38 \%$ at 2008 at their tertiary care hospitals. [21]

Previous CS was the most important indication for CS in the past three years to be $58.1 \%$ in $2013,52.3 \%$ in 2014 and 
reach $52.9 \%$ in 2015 , and the other indications make little contribution for indication of cesarean section, the second larger contribution for indication of cesarean section in 2013 was cephalopelvic disproportion $9.4 \%$, in 2014 was failed trial $9 \%$, in 2015 was failed trial $8.9 \%$. Table 1

These findings were similar to that of Alaa-Eldin Ebrashy et al and El Khyat et al at Cairo University where Repeat cesarean section (RCS) was the main indication and a large proportion of patients were having previous one cesarean section with an incidence of about $43.5 \%$ in the past 5 years.[19, 20]

Betrán et al (2007) showed a $29.2 \%$ CS rate in Latin America and the Caribbean.[2] The 2008 Demographic and Health Survey in Egypt also showed that the CS rate was about $25 \%$ nationwide and $37 \%$ in urban areas. [22] More recently, Egyptian Ministry of Health and Populations estimated the general Caesarean rate in 2014 national survey which was estimated by El-Zanaty and her associates to be more than $50.8 \%$ of all deliveries which may reach up to $60 \%$ in some urban areas. [9] so there is shocking increase in rate of cesarean.

By application of Modified Robson criteria [17, 18], group five (Previous Caesarean section, singleton cephalic, $\geq 37$ weeks) was the most important, either who was in spontaneous labour ( 2013- 18.1\%),(2014- 17.4\%), (2015$17.4 \%$ ) or CS before labour (2013-28.5\%), (2014$26 \%),(2015-25.8 \%)$ but there is no patients with induced labour, while group two (Nullipara, singleton cephalic, $\geq 37$ weeks) are the second most important either induced labour or CS before labour. Table 2

While induced labour in group five to ten were $0 \%$ in the three years, and so there is no trial of induction of labour in Tanta University Hospitals in patients with breech presentation, other malpresentaions, multiple pregnancy, previous scar and patients with IUGR or any other indication of preterm termination pregnancy, and this may account for the rising rate of CS in Tanat University Hospitals, and the application of protocol of induction of labour in the previous conditions may decrease the rising rate of cesarean section, but also may contribute to increase the rate of fetal and maternal complications. Table 2

In Egypt a study was done at Assuit University Hospitals using Modified Robson criteria where Caesarean section rate was $32 \%(443 / 1357)$ in 2008 and increased to $38 \%$ $(626 / 1628)$ in 2011 . The most common indication of CS at both time intervals was a previous caesarean delivery. Group 5 was the largest contributor $(30 \%)$ to the overall CS rate, followed by Groups 1 and 4 (10\% each). [23]

But Modified Robson criteria had many limitations as this classification disable the analysis of cesarean section by request [24] or even some morbid conditions as placenta previa, also neglect the analysis of some medical conditions, method used for labour induction and cause of prematurity.

The complications rate did not differ much between CS and vaginal delivery, with the commonest complication following vaginal delivery is breaking of episiotomy scar followed by genital organ injury, and the most common complication following cesarean section was infection complications followed by breaking of pfennestiel incision. Table 4

Driul L et al (2010) had a retrospective analysis of one year of cesarean sections at the Gynecology-Obstetrics Clinic of the University of Udine during 2006 showed that cesarean sections rate was $34.5 \%$, of which $42.1 \%$ were elective CS, $21.1 \%$ emergency antepartum CS, and $36.8 \%$ intrapartum $\mathrm{CS}$. The principal reason for CS delivery was previous CS in elective CS, gestational hypertension in emergency antepartum CS, and cardiotocographic alterations in emergency intrapartum CS. [25]

Santhanalakshmi et al (2015) analyzed indications of cesarean section over a period of 4 years at the Department of Obstetrics and Gynecology Karpaga Vinayaga Institute of Medical sciences and Research center, Maduranthagam, Tamil Nadu, India where the incidence of cesarean section was $12.5 \%$. The commonest indication for CS was repeat cesarean $(43 \%)$ followed by CPD $(15 \%)$. The commonest complications were primary hemorrhage and wound infection. [26]

The study has limitations, as it cannot precisely indicate the rate of cesarean section in the serving area as this retrospective study based on the record of Tanta university hospital only, but the rate of cesarean section is much higher in other private hospital with many fake indications.

Also this study lack the antenatal record of the patients, lack the financial effect of this high rate of cesarean section, neglect the successful trial of normal vaginal birth after cesarean section.

\section{Conclusion}

Although the rate of cesarean section was so high at Tanta University Hospitals and much higher than WHO recommendation for developing countries but still comparable to other Egyptian tertiary hospitals and to that of Egyptian Ministry of health. The rate of cesarean section shows minimal but continuous rise in the past three years so several attitudes must be taken to decrease that rate including more use of induction of labour, introduction of protocol of VBAC, health education of mother and special attention for hazards of cesarean section including placenta accreta.

\section{Acknowledgement}

We would like to thank our residents of Obstetrics and Gynecology department for their great help in collection of required data. Great thanks to Dr Ahmed Elkhyat assistant lecturer of Obstetrics and gynecology, Tanta University for his encouragement and statistical management.

\section{References}

[1] Dosa L. Caesarean section delivery, and increasingly popular option. Bull World Health Organ. 2001; 79: 1173-1175. 
[2] Betrán AP., Merialdi M., Lauer JA., Bing-Shun W., Thomas J., Van Look P., Wagner M. Paediatr Perinat Epidemiol. Rates of caesarean section: analysis of global, regional and national estimates. Paediatr Perinat Epidemiol. 2007; 21, 98-113.

[3] Kaimal AJ, Kuppermann M. Decision making for primary cesarean delivery: the role of patients and provider preferences. Semin Perinatol, 2012. 36: 384-389.

[4] Betrán AP, Ye J, Moller A-B, Zhang J, Gülmezoglu AM, Torloni MR. The Increasing Trend in Caesarean Section Rates: Global, Regional and National Estimates: 1990-2014. PLoS ONE. 2016. 11 (2): e0148343.

[5] Hacettepe University Institute of Population Studies (2014), "2013 Turkey Demographic and Health Survey". Hacettepe University Institute of Population Studies. T. R. Ministry of Development and TÜBĐTAK, Ankara, Turkey.

[6] Ono T, Matsuda Y, Sasaki K, Satoh S, Tsuji S, Kimura F, Murakami T. Comparative analysis of cesarean section rates using Robson Ten-Group Classification System and Lorenz curve in the main institutions in Japan. J Obstet Gynaecol Res. 2016 Sep 19.

[7] Einarsdóttir K, Ball S, Pereira G, Griffin C, Jacoby P, de Klerk N, Leonard H, Stanley FJ. Changes in Caesarean Delivery Rates in Western Australia from 1995 to 2010 by Gestational Age at Birth. Paediatr Perinat Epidemiol. 2015; 29: 290-8.

[8] Luz G., José M., Jeremy A., Ana P., Mario M. Fernando A. The Global Numbers and Costs of Additionally Needed and Unnecessary Caesarean Sections Performed per Year: Overuse as a Barrier to Universal Coverage. World Health Report (2010), Background Paper, 30.

[9] Ministry of Health and Populations [Egypt], El-Zanaty Associates [Egypt], ICF International. The 2014 Egypt demographic and Health Survey (2014 EDHS). Main Findings. Cairo, Egypt 2015.

[10] Yassin K., Saida G. Levels and Determinants of Caesarean Deliveries in Egypt: Pathways to Rationalization. Internet Journal of World Health and Societal Politics. 2012; 7, 1-8.

[11] Zwecker P, Azoulay L, Abenhaim HA. Effect of fear of litigation on obstetric care: a nationwide analysis on obstetric practice. Am J Perinatol. 2011; 28: 277-84.

[12] Ellerstein S, Feldman S, Duan T. China's 50\% caesarean delivery rate: is it too high? BJOG. 2015; 122: 160-4.

[13] Mi J, Liu F. Rate of caesarean section is alarming in China. Lancet. 2014; 383 (9927): 1463-4.

[14] Raisanen S, Gissler M, Kramer MR, Heinonen S. Influence of delivery characteristics and socioeconomic status on giving birth by caesarean section - a cross sectional study during
2000-2010 in Finland. BMC Pregnancy and Childbirth. 2014; 14 (1).

[15] Macfarlane A, Blondel B, Mohangoo A, Cuttini M, Nijhuis J, Novak Z, et al. Wide differences in mode of delivery within Europe: risk-stratified analyses of aggregated routine data from the Euro-Peristat study. BJOG. 2015.

[16] Grobman WA, Lai Y, Landon MB. The change in the rate of vaginal birth after caesarean section. Paediatr. Perinat. Epidemiol. 2011; 25, 37-43.

[17] Robson MS. Classification of caesarean sections. Fetal Matern Med Rev. 2001; 12: 23-39.

[18] Dan F., Debra Sh, Michael R. Classification of Caesarean Sections in Canada: The Modified Robson Criteria J Obstet Gynaecol Can 2012; 34, 976-979.

[19] Alaa-Eldin E., Ahmed K., Adel N., Wael F., Ahmed S. caesarean Section In A University and General Tertiary Hospitals in Cairo; Egypt: Rates, Indications and Limits. Kasr Al-Aini Journal of Obstetrics \& Gynecology. 2011; 2, 45-49.

[20] Waleed El-Khayat; Doaa Adel; Moustafa Abd El-Bar; Mohamed Waly. Cesarean Section Rate at a Tertiary University Hospital in Egypt in Five Years Period (2008 2012). KAJOG; Kasr Al-Aini Journal Of Obstetrics \& Gynecology. 2013. 4 (3). 66-74.

[21] Ihab Serag, Allam Ihab, Adel Gomaa, Hisham Mohamed Fathi, Ghada Fathi, Mahmoud Sukkar. Incidence of emergency peripartum hysterectomy in Ain-shams University Maternity Hospital, Egypt: a retrospective study. Arch Gynecol Obstet (2014) 290: 891-896.

[22] El-Zanaty F. Ann W. Egypt Demographic and Health Survey 2008. Cairo, Egypt: Ministry of Health.

[23] Abdel Aleem H, Shaaban OM, Hassanin AI, Ibraheem AA. Analysis of cesarean delivery at Assiut University Hospital using the Ten Group Classification System. Int J Gynaecol Obstet. 2013; 123 (2): 119-23.

[24] Gossman GL, Hoesch JM, Tanfer K. Trends in maternal request cesarean delivery from 1991 to 2005 . Obstet Gynecol 2006; 108: 1506-1516.

[25] Driul L., Londero AP., Salvador S., Fruscalzo A., Peris Bhat SA., Citossi A., Fabiani G., Bertozzi S., Marchesoni D. Retrospective analysis of one year of cesarean sections: indications and risk factors associated with intrapartum cesarean section, Minerva Ginecol. 2010; 62, 403-14.

[26] Santhanalakshmi C. Vijayalakshmi G. Chakravarthy A. Retrospective Analysis of Cesarean Section in a Tertiary Care Hospital, international Journal of Science and Research 2015; 4, 9-12. 